\title{
Shifting the Balance: Engaging Students in Using a Modeling Tool to Learn about Ocean Acidification
}

\author{
Tom Bielik ${ }^{1 *}$, Dan Damelin ${ }^{2}$, Joseph S. Krajcik ${ }^{1}$ \\ ${ }^{1}$ Michigan State University, East Lansing, Michigan, USA \\ ${ }^{2}$ The Concord Consortium, Concord, Massachusetts, USA
}

Received 18 May 2018 - Revised 6 August 2018 - Accepted 9 October 2018

\begin{abstract}
Modeling is one of the core scientific and engineering practices described in $A$ Framework for K-12 Science Education. Students are expected to construct, use, evaluate, and revise their models to make sense of phenomena or to find solutions to problems. Technology tools can support the development of students' modeling practice when learning about environmental issues. This study investigates the incorporation of an online computational modeling tool in a middle school curricular unit focusing on ocean acidification. We present the advantages and challenges experienced by students and teachers while engaging in the unit and using the modeling tool. Our results indicate that integrating the modeling tool in the ocean acidification curricular unit facilitates students' interest and engagement in environmental responsibility and focused students' attention toward human involvement and impact on the environment. Students perceived the tool and the curricular unit to be relevant to their lives and important in promoting their content learning and modeling practice. However, students and teachers reported several challenges, mostly related to the complexity of using the modeling tool and working with the resulting graphs and charts. We discuss these advantages and challenges and suggest recommendations for supporting students' modeling practice when learning about environmental issues.
\end{abstract}

Keywords: modeling practice, technology, ocean acidification

\section{INTRODUCTION}

"We learn by using it, learning about science by using the models."

A seventh-grade student who participated in this study made this insightful comment, reflecting the core goal of developing and using the modeling tool that is the focus of this paper. In order to gain deep appreciation of the modeling practice, students should be socially engaged in articulating, communicating, and critiquing their ideas by creating, using, revising, and sharing their models to explain phenomena and design solutions.

Scientific modeling (hereafter referred to as "modeling") is a key scientific and engineering practice emphasized in the latest science education science standards (Harrison \& Treagust, 2000; NRC, 2012). Scientists develop and use models to communicate and critique their ideas, and students are likewise expected to develop, use, and revise their models to communicate and critique their ideas in the classroom (Nersessian, 2002; Passmore, Gouvea, \& Giere, 2014). By the end of the twelfth grade, students are expected to construct models to explain phenomena and use them to test, design solutions, refine their models in light of new knowledge, and discuss the limitations of models (NRC, 2012).

Scientific models are broadly defined as abstract representations of systems that are used to explain and predict phenomena, comprised of variables and the relationships between them (Schwarz, 2009). Engaging students in modeling should build their cognitive and epistemic scientific knowledge and understanding. The goal of modeling is to test ideas by representing systems of connected processes and evaluating them with real-world evidence

(C) 2019 by the authors; licensee Modestum Ltd., UK. This article is an open access article distributed under the terms and conditions of the Creative Commons Attribution License (http://creativecommons.org/licenses/by/4.0/). \tbielik@msu.edu (*Correspondence) \ddamelin@concord.org \krajcik@msu.edu 


\section{Contribution of this paper to the literature}

- This paper contributes to the existing literature on using technology tools to promote students' modeling practice by adding a new tool and approach to teach students about environmental issues. This paper provides evidence for the advantages and challenges of using an online modeling tool, thereby making the case for the possible contribution of the modeling practice to students' positive attitudes, interest and engagement with environmental issues such as ocean acidification. Altogether, this paper should be of interest for researchers, policy-makers and practitioners who focus on promoting students' modeling practice and environmental literacy using advanced technological learning tools.

(Windschitl, Thompson, \& Braaten, 2008). Students who are provided with meaningful opportunities to engage in modeling should also develop their epistemic understanding about scientific models, mainly that they serve as a tool for thinking about systems rather than object description, and that models are never complete and represent the current consensus understanding based on empirical evidence. Students can best learn about modeling when the opportunities that they have to engage in modeling are engaging, interesting and built on their prior knowledge. Students require substantial support and multiple experiences to fully develop their modeling practice, which can be scaffolded by social negotiation when engaging with complex models and abstract models (Harrison \& Treagust, 2000).

In most science classrooms, students do not have sufficient opportunities to engage in modeling, and both teachers and students often lack understanding of the modeling practice (Schwarz, 2009; Windschitl et al. 2008). Often, teachers and curricular materials fail to stress the limitations of models and assume students understand that models are never complete and always negotiable. Most students view scientific models as realistic algorithmic representations that could be used to memorize the correct answer, rather than as cognitive explanatory tools for sharing and critiquing ideas (Harrison \& Treagust, 2000). Several studies investigated how to support students in developing their modeling practice, and recommendations for appropriate learning progressions have been published (Lehrer \& Schauble, 2006; Schwarz et al., 2012). Schwarz (2009) suggest an instructional sequence for engaging students in modeling that includes the core elements of modeling: constructing, using, evaluating, and revising models. The sequence starts with introducing a driving question and phenomena, creating initial models, performing investigations to empirically test the models, revising the model based on new ideas, and using the model to predict or explain other phenomena. This instructional sequence was used to develop the curricular unit presented in this paper.

Technology tools, such as computer-based simulations, hold the potential to support students' modeling practice and learning (NRC, 2012). Fretz et al. (2002) demonstrate how using computational software supported students in modeling complex dynamic systems. Other studies found that computer-based visualization modeling tools support students' reasoning and explanation capabilities (Nersessian, 1999), affect student learning and understanding of molecular chemistry ideas (Wu, Krajcik, \& Soloway, 2001), and increase students' interest and engagement in science (Ainsworth, 2006). Using technology tools is a key feature in Project Based Learning (PBL), helping students participate in activities that are normally beyond their ability. Technology tools support students in actively constructing knowledge and provide an interactive information-rich environment (Krajcik \& Shin, 2014; Marx, Blumenfeld, Krajcik, \& Soloway, 1997).

Integrating innovative technology tools requires addressing systemic issues such as usability, scalability, and sustainability of the tool in order to make their use widespread in science classrooms (Fishman, Marx, Blumenfeld, Krajcik \& Soloway, 2004). Blumenfeld, Fishman, Krajcik, Marx, and Soloway (2000) carried out a large-scale research project in which technology tools were integrated in PBL-aligned curricular units designed for reform teaching in an urban middle school. They suggested a framework for incorporating computational tools in science classes that focus on student-centered learning and inquiry. They identified several challenges when shifting schools and teachers towards using these tools, mostly concerning user capability, policy and management, and organizational culture issues. Quintana et al. (2004) suggest a scaffolding design framework and pedagogical supports for effective integration of computer-based software in science classrooms. This framework is empirically grounded in theoretical concepts of cognitive apprenticeship, active learning, and social constructivism to scaffold students' knowledge and understanding when using technology tools.

Classroom engagement is an important factor contributing to students' cognitive learning, goal orientation, and motivation (Hidi \& Renninger, 2006). Engagement is content specific and comprises behavioral (interest, belonging, value), affective (positive emotions), and cognitive (self-regulation, investment in learning) components (Fredricks \& McColskey, 2012). However, research has shown that students become more disengaged as they progress in school grades (Skinner et al., 2008). Three-dimensional learning (NRC, 2012) and PBL-aligned learning materials were found to increase students' engagement in science lessons (Schneider et al., 2016). 
Promoting awareness of human impact on the environment is one of the main goals of environmental education. This can be achieved by increasing students' awareness, knowledge, and attitudes towards environmental and sustainability issues (Shepardson et al., 2001). Many studies demonstrate that participation in environmental programs increases students' pro-environmental perception, concerns, emotions, values, and beliefs - all focusing on sustainability and human impact on natural environmental systems (Johnson \& Manoli, 2008; Manni et al., 2017). Not many studies have investigated how to support students in building a model of environmental issues or on tools that could be used to scaffold students' understanding and development of proenvironmental attitudes.

Ocean acidification has emerged as an important environmental threat (Doney et al., 2009). Increasing levels of atmospheric $\mathrm{CO}_{2}$ result in increasing oceanic levels of carbonic acids, making the ocean more acidic and harming ecological systems. Scientific research suggests that ocean acidification may affect many calcifying marine species, such as corals, which could impact large food webs (Abbasi \& Abbasi, 2011). There is a need to increase awareness and understanding of the possible dangers of ocean acidification, and students should learn about this issue in both formal and informal education systems (Fauville et al., 2013).

Few studies have examined how using modeling tools can promote students' interest and engagement in science class, in particular in the context of environmental issues, and what advantages and challenges students face when using modeling tools integrated in current standards-based curricular materials. This paper presents one classroom's enactment of an online open-access modeling tool that was developed to support secondary students in developing and using models. The tool was integrated in a middle school PBL-based curricular unit that focused on deforestation and ocean acidification, aligned with current science education standards (NRC, 2012).

To investigate the possible effect of integrating a modeling tool in curricular materials about environmental issues on students' interest and engagement in science classrooms, two research questions were explored: (i) What were the participants' perceived advantages and challenges of learning the unit? and (ii) What were the participants' perceived advantages and challenges of using the modeling tool and engaging in the modeling practice? To address these questions, we investigated the enactment of a curricular unit that was designed to include several opportunities for students to create, use, and revise their models using a newly developed online modeling tool.

\section{The Modeling Tool}

This study is part of a National Science Foundation (NSF)-supported project aimed at supporting secondary students' modeling practice by developing open-access online modeling software and integrating it in Next Generation Science Standards (NGSS)-aligned curricular materials. The project is a collaborative work between Michigan State University and the Concord Consortium.

The modeling tool, SageModeler ${ }^{1}$, was designed to support students in constructing, using, evaluating and revising their models to explain phenomena and design solutions while focusing on system thinking and using a range of visual representations such as images, labels, tables, and graphs (Damelin, Krajcik, McIntyre, \& Bielik, 2017). The tool allows students to create models and run simulations to answer driving questions. The variables, represented by student-selected images and verbal description, are connected with arrows and the relationships are defined using semi-quantitative descriptions. After setting up variables and defining relationships, students can run quantitative simulations in which they manipulate the independent variables to receive output as graphs. Students can use and revise their models while working with empirical data from different sources, such as classroom experiments or authentic research data. The tool was developed to support students' modeling practice, based on learning progressions described in A Framework for K-12 Science Education and empirical research (NRC, 2012; Schwarz et al., 2012), and designed to be easy to use, intuitive, interactive and visually engaging. SageModeler was integrated in CODAP, the Common Online Data Analysis Platform, a graphing and data analysis platform that takes the outputs generated by the model and any other data source to combine them into a single analytic environment (Finzer \& Damelin, 2016).

The study presented in this paper was the first classroom enactment of the tool. Several cycles of revisions to the tool have been carried out since the enactment, and most of the computational and technical issues noted below have been addressed and resolved.

\section{Ocean Acidification Curricular Unit}

A curricular unit designed for approximately two to three weeks was developed by the research team to be enacted in middle schools. The unit was developed based on core features of PBL, which includes starting with relevant driving questions, focusing on learning goals that align with science standards, using inquiry and scientific practices to explore the driving question, engaging in collaborative activities, scaffolding learning by using various 
Table 1. Lessons of the ocean acidification unit

\begin{tabular}{|c|c|c|c|}
\hline Lesson \# & Lesson level learning performances & Core ideas & Main activities \\
\hline 1 & $\begin{array}{l}\text { Develop a model to describe the } \\
\text { relationship between forest ecosystems } \\
\text { and fish viability. }\end{array}$ & $\begin{array}{l}\text { * Carbon naturally flows through Earth's } \\
\text { spheres. } \\
\text { * Changing the natural flows of carbon can } \\
\text { impact living organisms, including humans. } \\
\text { * Models help describe and predict } \\
\text { changes in a system. }\end{array}$ & $\begin{array}{l}\text { * Watch fishermen videos and } \\
\text { introduce the driving question. } \\
{ }^{*} \text { Create initial models using the } \\
\text { modeling tool. }\end{array}$ \\
\hline 2 & $\begin{array}{l}\text { Construct an argument for why plants } \\
\text { are important for reducing the } \\
\text { atmospheric } \mathrm{CO}_{2} \text { level. }\end{array}$ & $\begin{array}{l}\text { * Plants are part of the biosphere and } \\
\text { absorb } \mathrm{CO}_{2} \text {. } \\
{ }^{*} \mathrm{CO}_{2} \text { level decreases when } \\
\text { photosynthesizing plants are introduced to } \\
\text { a system. }\end{array}$ & $\begin{array}{l}\text { * Perform investigation on effect } \\
\text { of plants on water acidity. } \\
\text { * Revise models to include } \mathrm{CO}_{2} \\
\text { absorption by plants. }\end{array}$ \\
\hline 3 & $\begin{array}{l}\text { Explain how human activities, such as } \\
\text { deforestation and combustion } \\
\text { activities, can affect } \mathrm{CO}_{2} \text { transfer } \\
\text { between Earth's spheres. }\end{array}$ & $\begin{array}{l}\text { * Deforestation can affect the biosphere's } \\
\text { capability to uptake } \mathrm{CO}_{2} \text {. } \\
\text { * Combustion reactions, using the products } \\
\text { of deforestation, contribute to change in } \\
\text { atmospheric } \mathrm{CO}_{2} \text { concentrations. }\end{array}$ & $\begin{array}{l}\text { * Read a paper and answer } \\
\text { questions about deforestation. } \\
\text { * Revise models to include } \\
\text { deforestation, human-induced } \\
\mathrm{CO}_{2} \text { emission, and level of } \\
\text { atmospheric } \mathrm{CO}_{2} \text {. }\end{array}$ \\
\hline 4 & $\begin{array}{l}\text { Construct an explanation for how } \\
\text { combustion reactions can change } \\
\text { water acidity level and cause ocean } \\
\text { acidification. }\end{array}$ & $\begin{array}{l}\text { * Increase in atmospheric } \mathrm{CO}_{2} \\
\text { concentration causes ocean acidification. } \\
\text { * Models are intended to be revised based } \\
\text { on new findings and knowledge. }\end{array}$ & $\begin{array}{l}\text { * Perform investigation on } \\
\text { transfer of } \mathrm{CO}_{2} \text { from air to water. } \\
{ }^{*} \text { Revise models based on } \\
\text { analysis of authentic data from } \\
\text { an oceanic research station. }\end{array}$ \\
\hline 5 & $\begin{array}{l}\text { * Analyze and interpret data to } \\
\text { describe the relationship between } \\
\text { water acidity and decalcification of } \\
\text { shellfish organisms. } \\
{ }^{*} \text { Engage in argument to describe the } \\
\text { effect of ocean acidification on the } \\
\text { environment. }\end{array}$ & $\begin{array}{l}\text { * Ocean acidification causes slower growth } \\
\text { rate and decalcification of marine calcifying } \\
\text { species, which can affect biodiversity, } \\
\text { ecological systems, food webs, and human } \\
\text { flourishing. }\end{array}$ & $\begin{array}{l}\text { * Perform investigation on effect } \\
\text { of water acidity on seashells' } \\
\text { decalcification. } \\
\text { * Revise models to include effect } \\
\text { of ocean acidification on } \\
\text { ecosystems. }\end{array}$ \\
\hline
\end{tabular}

learning technologies, and creating tangible artifacts (Krajcik \& Shin, 2014). All these are aimed at engaging learners in developing usable knowledge to make sense of phenomena (Krajcik, McNeill, \& Reiser, 2008).

To align with the three-dimensional learning goals described in A Framework for K-12 Science Education and the Next Generation Science Standards (NRC, 2012; NGSS Lead States, 2013), one middle school Performance Expectation was chosen as the main focus of the unit (MS-LS2-3: Develop a model to describe the cycling of matter and flow of energy among living and nonliving parts of an ecosystem). Unpacking the three-dimensional ideas (science and engineering practices, disciplinary core ideas, and crosscutting concepts) described in the Performance Expectation was collaboratively done by the project researchers in an iterative process, following the procedural process described by Krajcik, Codere, Dahsah, Bayer, and Mun (2014a).

The unit focused on the ideas of $\mathrm{CO}_{2}$ transfer between Earth's spheres, deforestation, and the effect of ocean acidification on seashells, ocean ecosystems, and human flourishing (Bielik, Damelin, \& Krajcik, 2018). The anchoring phenomena of the unit emerges from short videos presented to the students in the first lesson, in which shellfish fishermen talk about the decreasing amount of catch in recent years. From this anchoring phenomena, students are presented with the driving question of the unit: "Why do fishermen need forests?" and are asked to share their initial ideas to explain the phenomena and to ask additional questions related to the driving question using a Driving Question Board (Weizman et al., 2008). The activities were designed to engage students in collaborative investigations in order to find an explanation to the driving question. The learning sequence comprised several stages of building, testing, and revising their models using the modeling software, each stage requiring increasingly sophisticated features of the modeling tool and concepts of modeling. These opportunities to engage with the modeling tool included activities such as interpreting results of classroom experiments, testing the models in light of data from authentic oceanic research, and revising the models based on feedback from the teacher and class peers. The lesson level learning performances, core ideas, and main activities of the ocean acidification unit are presented in Table 1.

The activities were embedded in the Concord Consortium's STEM Resource Finder online platform that included links to the modeling tool with other activities such as videos, interactive questions, etc. This provided students with an opportunity to save, share, and revise their models, and provided the teachers and researchers with access to student artifacts. Several examples of students' final models at the end of the ocean acidification unit are presented in Figure 1. 


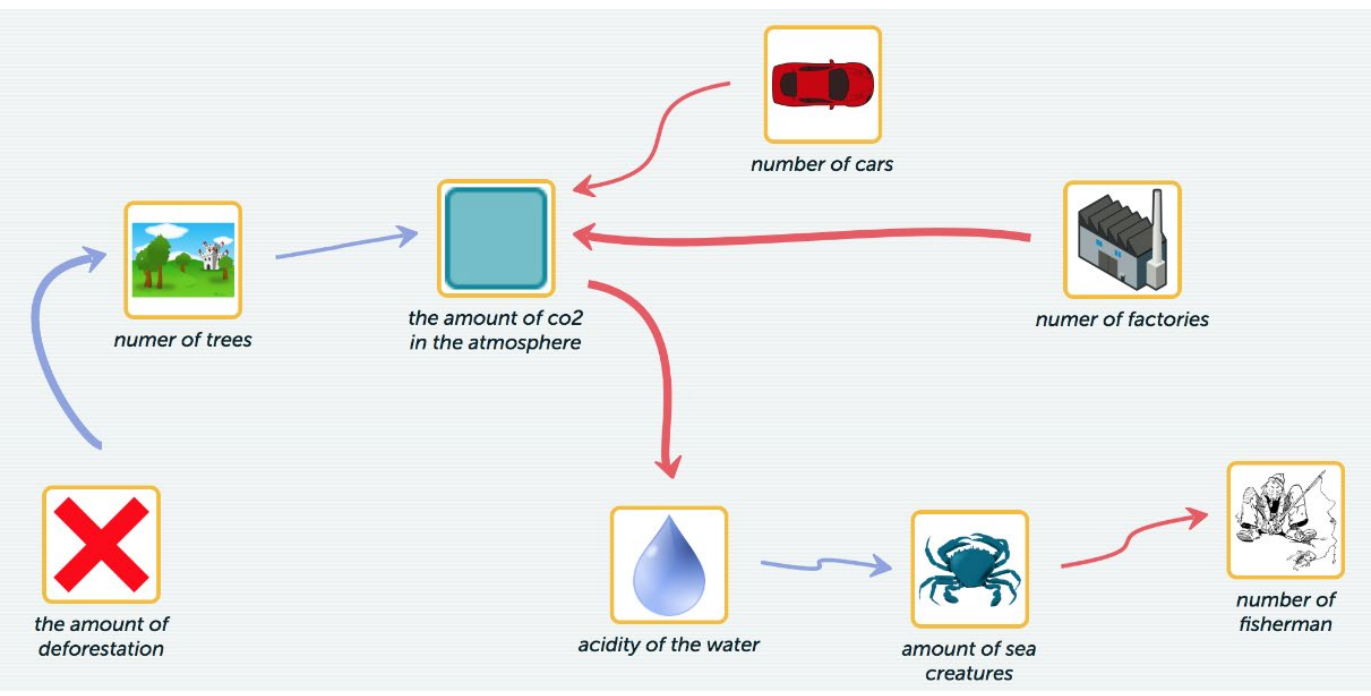

(a)

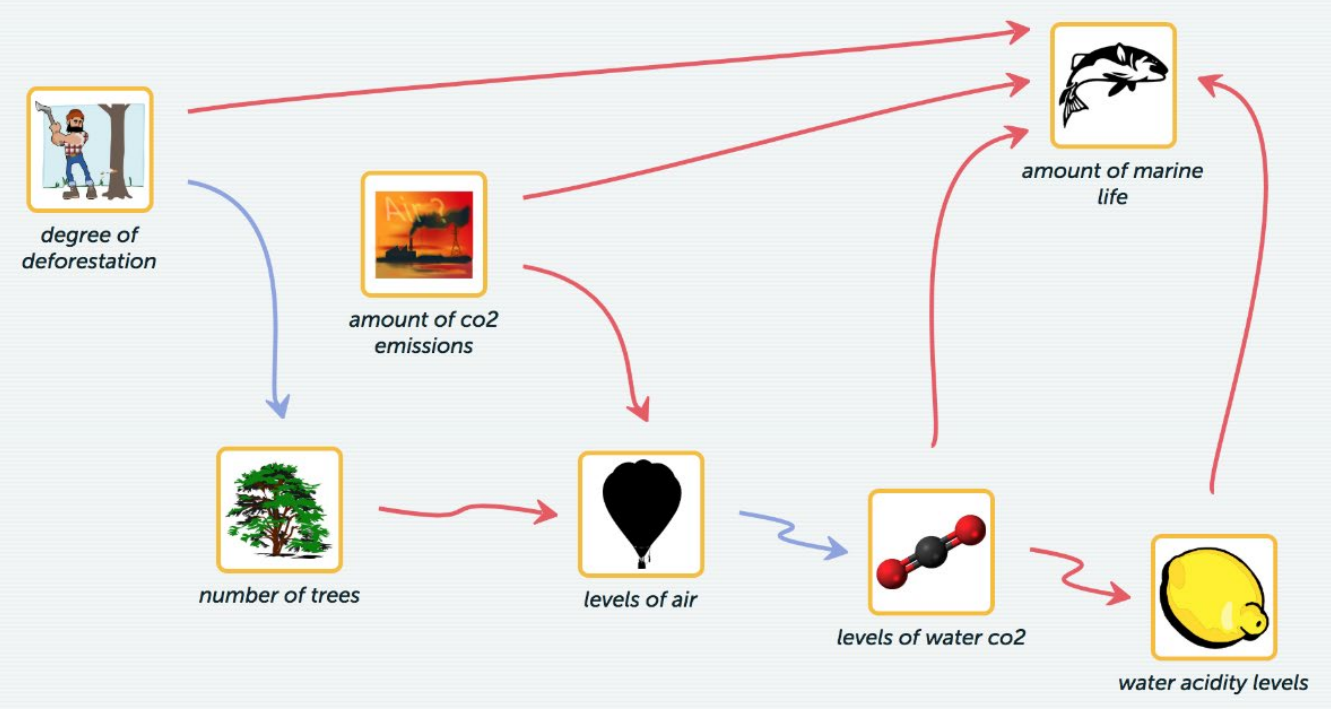

(b)

Figure 1. Examples of students' final models of the ocean acidification unit using the modeling tool (red arrows represent increasing relationships; blue arrows represent decreasing relationships) 


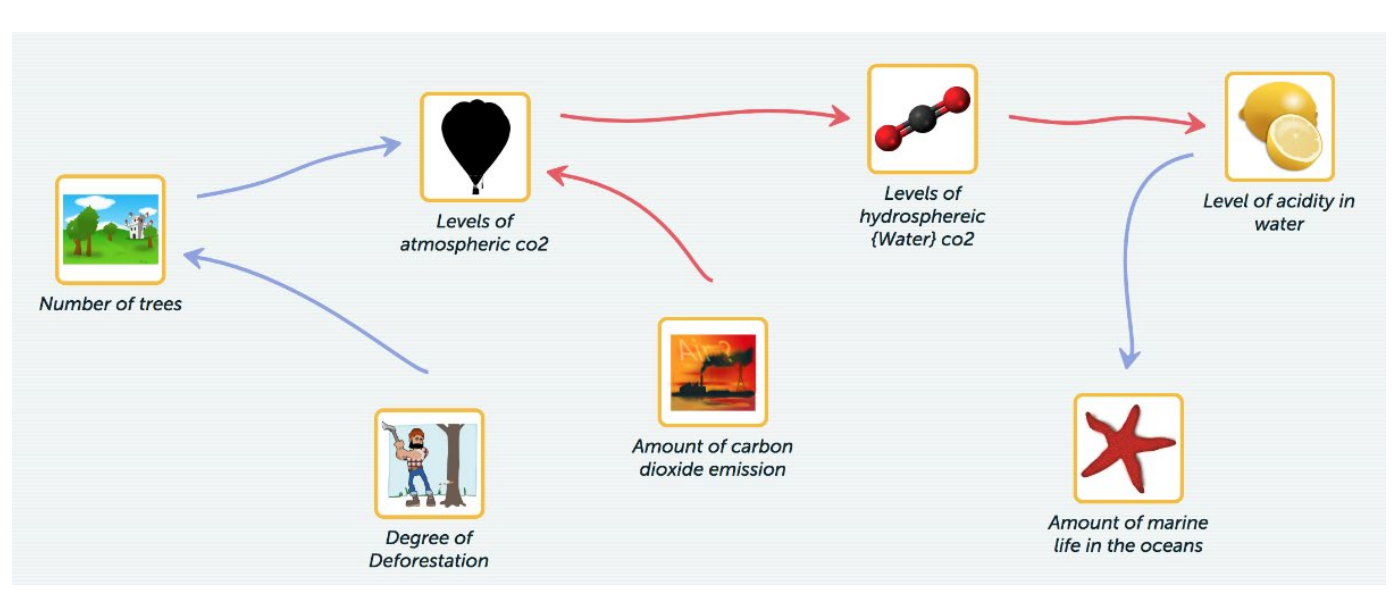

(c)

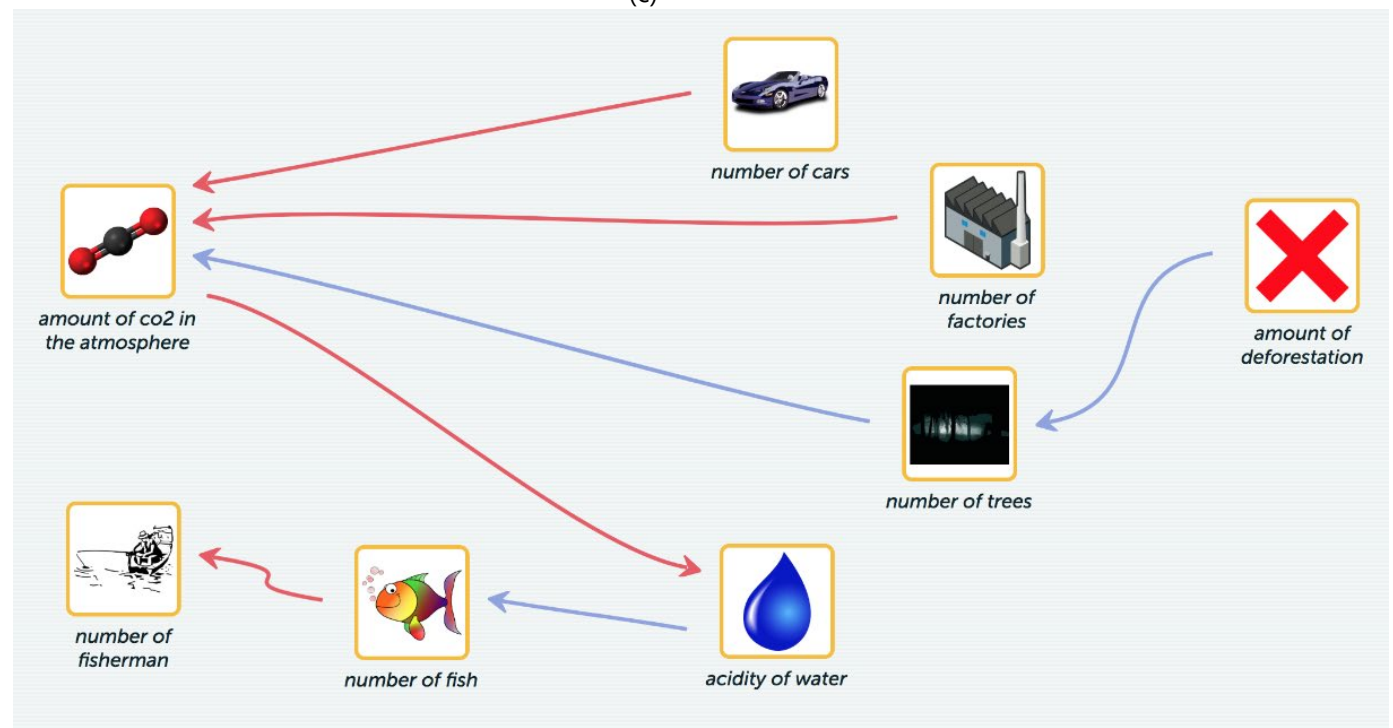

(d)

Figure 1 (continued). Examples of students' final models of the ocean acidification unit using the modeling tool (red arrows represent increasing relationships; blue arrows represent decreasing relationships)

\section{METHODOLOGY}

\section{Participants}

Results presented in this study were collected during the enactment of the ocean acidification unit in one rural low socioeconomic level middle school in Michigan, USA, during the spring of 2016. Both of the school's seventh grade science teachers volunteered to participate in this study. Mrs. A. was an expert science teacher with 22 years of teaching experience. Mrs. F. was a novice teacher with four years of teaching experience. Mrs. A. was teaching 6 classes and a total of 158 students. Mrs. F. taught 2 classes and a total of 58 students. Teachers mentioned that most students have limited technology access and abilities, and that not many technological learning tools are used in typical science lessons. Neither of the teachers reported having previous experience or training in Project-Based Learning or three-dimensional learning. Both teachers participated in eight hours of a professional learning workshop prior to the enactment of the unit, where they were presented with the project goals, engaged with the modeling tool and curricular materials, and discussed how to support students in developing their modeling practice. The project researchers also provided additional face-to-face and online support to the teachers during the enactment. The enactment lasted approximately four weeks due to several canceled days at school and other school activities. 


\section{Tools and Methods}

This study is part of a design-based research that included iterative cycles of developing and testing the modeling tool and curricular materials. Results in this study address the first classroom enactment of the tool. Analysis included both qualitative and quantitative methods. Data was collected during and following the ocean acidification unit enactment and included the following tools and methods:

\section{Pre- and post-unit online student surveys}

To explore students' interest and perceptions about learning the unit and using the modeling tool, pre- and post-enactment anonymous online surveys were administered to all seventh-grade students immediately before and following the unit enactment. Surveys included identical five-point Likert scale items asking the students to rank their interest in the unit's topics from "not interested at all" to "very interested." Topics included biodiversity of species, the carbon cycle, ecological and environmental issues, human economy, human nutrition, deforestation, food webs, marine life ecosystems, and photosynthesis. A total of 172 students answered both the pre- and postsurveys.

Items in the survey were validated by three science education researchers by reaching full agreement. Students' responses were electronically collected and analyzed. Students' rankings of the Likert-scale items were analyzed using non-parametric Wilcoxon signed-rank test with continuity correction to find significant differences between surveys (Wilcoxon, 1945).

The post-survey also included two open-ended questions: "What was the most interesting part of the unit and why?" and "What was the most difficult or challenging part of the unit and why?" Students' responses were classified into emerging categories by three independent raters. Emerging categories were evaluated in several cycles of analysis by three science education researchers until consensus was reached among raters.

\section{Student and teacher interviews}

Following the enactment of the unit, semi-structured interviews with 10 volunteer students and the two teachers were performed and analyzed to expose the participants' perceptions of the advantages and challenges of using the modeling tool and curricular unit. Students were asked about the most interesting and challenging parts of the unit and the use of the modeling tool in the lessons (Appendix 1). Teachers were asked to reflect on the teaching of the unit and their students' experience during the enactment of the unit and while using the modeling tool (Appendix 2). Specific parts of the interviews, related to the research questions of this study, were transcribed and qualitatively analyzed for emerging themes. Initial analysis for emerging themes was performed by one of the authors. Those categories were triangulated with two other researchers to the point of full agreement.

\section{Students' written questions from "Question-at-the-door" activities}

In order to expose possible shifts in students' focus and interest during the unit's lessons, students' selfgenerated spontaneous pen-and-paper written questions were collected and analyzed. This "Question-at-the-door" activity included the following open-ended questions: "What new scientific questions can you think of following this lesson?" and "How would you go about finding an answer to these questions?" A total of 891 questions were written by the students and collected for analysis.

Students answered these questions at the end of the first lesson after they had created their initial models to explain the driving question (total of 347 questions), at the end of the second lesson after having performed the $\mathrm{CO}_{2}$ absorption by water plant experiment and revising their models (total of 276 questions), and at the end of the last lesson of the unit (total of 268 questions). Students' written questions were classified into emerging categories by three independent raters. Several cycles of validation were performed until consensus was reached among raters.

One of the categories that emerged from the data was questions related to environmental responsibility and human involvement. Questions that were classified into this category were further classified into the following emerging sub-categories: pollution and $\mathrm{CO}_{2}$ emissions, plants and deforestation, ocean acidification and water quality, and animal welfare. Examples for questions in each sub-category are presented in Table 2. 
Table 2. Categories, examples, and number of students' questions focusing on environmental responsibility and human involvement (out of a total of 891 questions)

\begin{tabular}{ll}
\hline Sub-category & Examples of students' questions (question number in brackets) \\
\hline $\begin{array}{l}\text { Pollution and } \\
\text { emissions }\end{array}$ & $\mathrm{CO}_{2}$ Why can't we find another source of energy rather than burning fossil fuels? [question \#399] \\
& Could scientists make a device that could collect toxins in the atmosphere? [question \#445] \\
& Should factories limit their pollution going out? [question \#476] \\
& How can we reduce the amount of waste going into our air? [question \#531]) \\
\hline Plants and deforestation & How can we stop all of this deforestation? [question \#228] \\
& How can we make the trees take in the carbon dioxide from inside the ocean? [question \#482] \\
\hline $\begin{array}{l}\text { Ocean acidification } \\
\text { water quality }\end{array}$ & and How can we help clean the ocean? [question \#447] \\
& How many trees are left and what can we do to preserve them? [question \#564] \\
& Why aren't more trees being planted? [question \#600] \\
\hline Animal welfare & Why do [we] have to harm the animals? [question \#65] \\
& Why do we do these things that kill other animal life? [question \#233] \\
& Why do people pollute the lakes if they know it kills the fish and animals in it? [question \#408]
\end{tabular}

\section{RESULTS}

To address the research questions, results are divided into two sections. The first section focuses on the perceived advantages and challenges of learning the ocean acidification unit. The second section focuses on the perceived advantages and challenges of using the modeling tool. These two sections should be viewed as two separate parts of the intervention in which the ocean acidification unit serves as the context for integrating the modeling tool. Some effects could be attributed to the unit and the activities in it, and other effects are related to the modeling tool itself and its features. However, the integration of both aspects provides the broad scope of results, which builds the basis for the discussion and conclusions focusing on supporting students' modeling practice using advanced computational tools integrated in curricular materials.

\section{Advantages and Challenges of Learning the Ocean Acidification Unit}

To explore participants' perceived advantages and challenges of learning the ocean acidification unit, students' answers to the online pre- and post-surveys, teacher and student post-enactment interviews, and students' spontaneous questions at the end of several lessons were analyzed. Results are presented in the three emerging categories: (i) content topics of the unit, (ii) activities in the unit, and (iii) environmental responsibility and relevance to daily lives.

\section{Content topics of the unit}

Significant increase in students' interest from the pre- to the post-surveys was found. Students' interest increased in topics that included biodiversity of species $(\mathrm{p}<0.05)$, carbon cycle $(\mathrm{P}<0.01)$, human economy $(\mathrm{P}<0.005)$, human nutrition $(\mathrm{P}<0.01)$, and deforestation $(\mathrm{p}<0.001)$. Some increase in students' interest, though not statistically significant, was found with the other topics, such as ecology and environmental issues, food webs, marine life ecosystem and photosynthesis (Figure 2). 


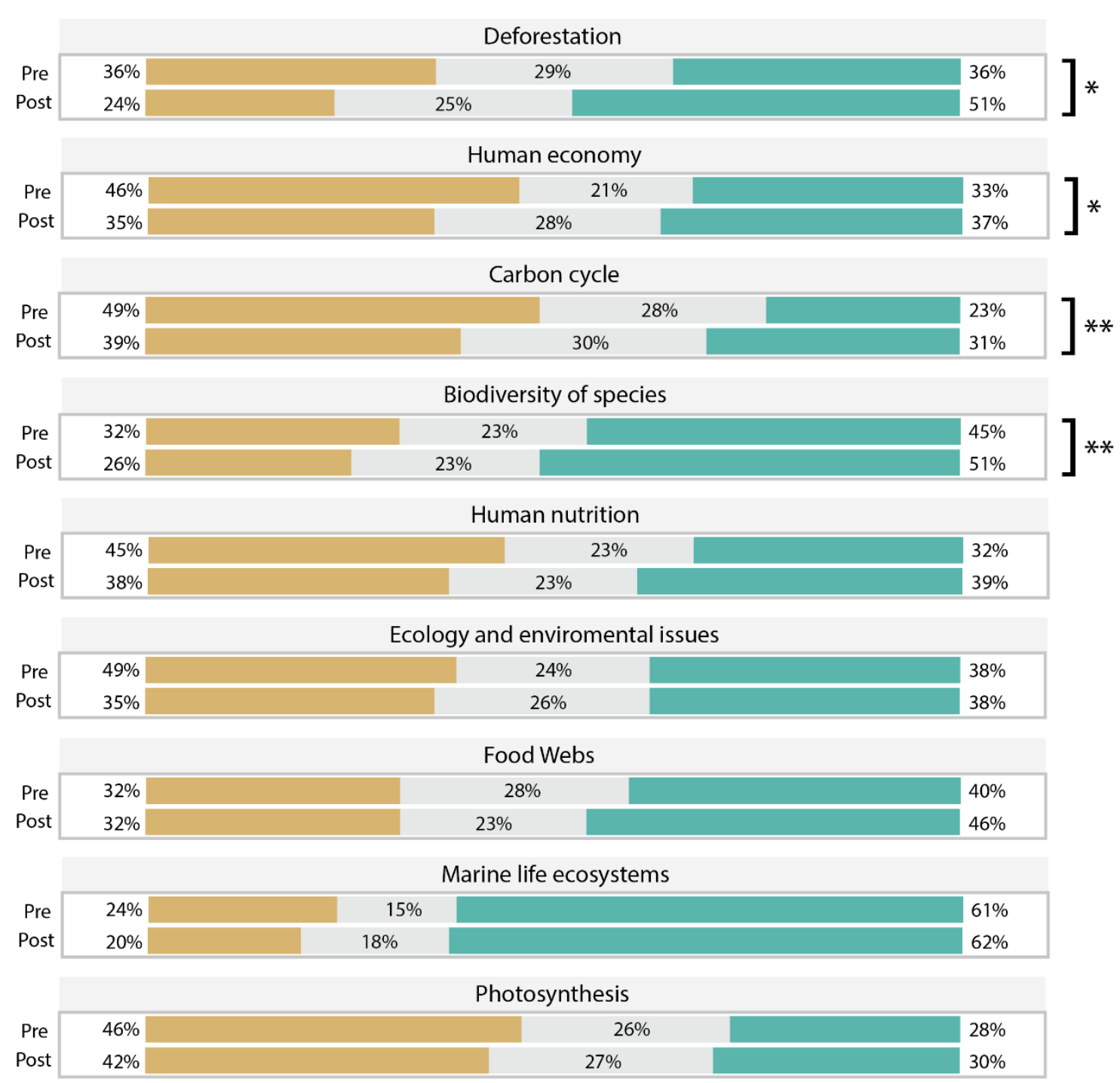

\section{Response Key}

Not interested at all / A little interested

Neutral

Interested / Very interested

Figure 2. Students' self-reported interest in content topics of the ocean acidification unit, based on pre- and post-enactment online surveys $(n=172) .{ }^{*}=p<0.005,{ }^{* *}=p<0.05$

These findings correlate with analysis of students' written answers to the open question in the online postsurvey: "What was the most interesting part of the unit?" Many of the students' responses mentioned marine life and ecosystems (19.8\% of the responses, e.g., student \#46: "The most interesting part was the way $\mathrm{CO}_{2}$ effected [affected] the sea life because I am really interested with marine biology"), $\mathrm{CO}_{2}$ sources and effects (18.6\% of the responses, e.g., student \#50: "I think the most interesting part of the carbon cycle lessons was probably that most $\mathrm{CO}_{2}$ doesn't necessarily come from humans but things such as cars and factories"), $\mathrm{CO}_{2}$ transfer between Earth's spheres (14.5\% of the responses, e.g., student \#94: "The most interesting part of the carbon cycle lessons is how the $\mathrm{CO}_{2}$ went up into the air and how it got to the water"), and ocean acidification (9.3\% of the responses, e.g., student \#36: "The most interesting part of the carbon cycle was, in my personal opinion, the effect of ocean acidification. This is so, as the effects of ocean acidification are astounding and terrible"). Several of the students also mentioned their interest in the content topics of the unit in their interviews, e.g., "Deforestation is interesting, I like to watch shows on discovery, the negative effect of deforestation (student \#2) and "To learn about $\mathrm{CO}_{2}$, acidity and oceans was interesting" (student \#10).

Learning about the unit's content topics was also considered challenging and difficult by some of the students and teachers. Almost $21 \%$ of students' responses to the post-survey question "What was the most difficult or challenging part of the unit?" focused on issues related to the content topics of the unit. Some challenges were related to the general learning of the unit and understanding the driving question (e.g., student \#76: “[it was 
difficult] getting to know exactly why the fishermen need forests"). Other students addressed the complexity of variables and relationships between them (e.g., student \#33: "The most difficult thing about the carbon cycle is knowing what causes it, people, factories, cars and what else there are probably a lot more but understanding what and how is the most challenging"). Other issues that were mentioned by the students focused on understanding the topics of the unit, such as $\mathrm{CO}_{2}$ transfer between Earth's spheres and ocean acidification (e.g., student \#50: "The most difficult part of the carbon cycle lesson was understanding how the $\mathrm{CO}_{2}$ from everyday scenarios was affecting the acidity of the ocean and its sea life").

In their interviews, both teachers mentioned the challenges their students had with understanding the content of the unit. Mrs. F. claimed that the chemistry concepts were too hard for her seventh-grade students, that there were too many variables to learn, and more prior knowledge was required by the students to fully understand the ideas in the ocean acidification unit. Mrs. A. also mentioned the cognitive difficulties her students faced during the enactment of the unit.

These results indicate that although most of the content topics of the unit were interesting for the students, some of the content ideas were cognitively complicated for them and might be beyond their understanding, due to lack of sufficient prior knowledge or using complex ideas that are beyond their cognitive capabilities.

\section{Activities in the Unit}

Some of the students mentioned the activities in the unit to be the most interesting part (11\% of the responses, e.g., student \#54 "When we were doing the ocean acidity demonstrations with the BTB [Bromothymol Blue]. It was the most interesting part because we got to see how $\mathrm{CO}_{2}$ affected the acidity in the water"). This was also mentioned by some of the students in their interviews, e.g., "The experiment with plant and indicator were interesting" (student \#7). Only about $5 \%$ of the students mentioned difficulties related to performing or understanding the activities in the unit in the post-survey (e.g., student \#66: "[it was difficult to understand] how the water with the plant changed color and everything"), and only one student mentioned this in his interview (student \#6: "Took a while to get the [ $\mathrm{CO}_{2}$ transfer] experiment, wasn't doing what it was suppose to... using the Hawaii data was a bit complicated, not too hard"). These results indicate that the activities and experiments in the unit were interesting and engaging for some of the students, and that most of the activities were perceived by the students as within their cognitive capabilities.

\section{Relevance to Daily Life: Environmental Responsibility and Human Involvement}

One issue that emerged from students' responses was relevance of the unit to their daily lives, focusing mostly on human involvement and impact on the environment, and human responsibility to protect the environment. These aspects were mentioned in 9.3\% of students' responses in the post-survey (e.g., student \#24: "The most interesting part about the carbon cycle is how much of the $\mathrm{CO}_{2}$ in our atmosphere and water is our fault from factories or even deforestation").

In their interviews, students mentioned that the unit was relevant to their lives and that they should be more active in protecting the environment. For example, student \#1 responded to the question "Do you think you can take something from what you've learned in the past few weeks to your own life?" that she should walk more instead of driving in cars, so that less $\mathrm{CO}_{2}$ is released to the air. In another example, the student focused on deforestation and the importance of saving the trees. The following segment is taken from the interview with student \#2:

Interviewer: "Was it interesting to learn about what we discussed in the lessons?"

Student: "Yeah, because I'm kind of interested in, like, the amount of deforestation. I like to watch the shows on discovery, and, like, the history channel. I like X-men, where they, like, cut down stuff, but now I see, like, how negative it is when they do that. Just take out a whole mountain side of trees."

Interviewer: "Do you think you learned something that will be helpful for you in your own life, things you do outside of school?"

Student: "Yeah, because, like, we live on a farm and everything, and we have a wood-burning stove. So, like, when we cut down trees and stuff, it's kind of like, it makes our woods shrink and shrink, and everything, like, parts of it. We've got a lot of places to cut, but it's still shrinking it, like, every once in a while we should plant a couple of trees and have them grow, and later on, when we could, like, cut those ones down, plant new ones."

In her interview, Mrs. F. also commented that the unit was engaging for her students because the environmental issues are relevant to their lives. This issue was also prominent in students' written questions at the end of the lessons, as detailed below.

Analysis of students' written questions in the activity "Question-at-the-door" at the end of lessons 1, 2, and the final lesson of the unit, revealed that many of the students' questions focused on environmental responsibility and engagement issues. Questions of this type were defined as questions in which there is a call for action to protect the 
Table 3. Distribution of students' questions focusing on environmental responsibility and engagement (total of 347 questions at the end of the first lesson, 276 questions at the end of the second lesson, and 268 questions at the end of final lesson)

\begin{tabular}{|c|c|c|c|}
\hline Category & $\begin{array}{l}\text { Number and \% of questions at } \\
\text { the end of lesson } 1\end{array}$ & $\begin{array}{l}\text { Number and \% of questions at } \\
\text { the end of lesson } 2\end{array}$ & $\begin{array}{l}\text { Number and \% of questions at } \\
\text { the end of final lesson }\end{array}$ \\
\hline $\begin{array}{lll}\begin{array}{l}\text { Pollution } \\
\text { emissions }\end{array} & \text { and } \mathrm{CO}_{2} \\
\end{array}$ & $26(7.49 \%)$ & $18(6.51 \%)$ & $43(16.05 \%)$ \\
\hline Animal welfare & $9(2.59 \%)$ & $3(1.09 \%)$ & 8 (2.99\%) \\
\hline $\begin{array}{l}\text { Ocean acidification and } \\
\text { water quality }\end{array}$ & $6(1.73 \%)$ & $6(2.17 \%)$ & $11(4.1 \%)$ \\
\hline Plants and deforestation & $4(1.15 \%)$ & $7(2.54 \%)$ & $13(4.85 \%)$ \\
\hline Total & 45 (12.96\%) & $34(12.31 \%)$ & 75 (27.98\%) \\
\hline
\end{tabular}

environment, a question regarding human impact on the environment, or a question about personal engagement related to environmental issues. From a total of 891 questions, 154 questions (17\%) were related to these issues. These questions were further classified, and several sub-categories emerged. Most of the questions focused on issues of pollution and $\mathrm{CO}_{2}$ emissions ( 87 out of 154 questions, $57 \%$ ). The rest focused on plants and deforestation (24 questions, $28 \%$ ), ocean acidification and water quality (23 questions, $25 \%$ ), and questions related to animal welfare (20 questions, $23 \%$ ).

When analyzing students' questions based on the lesson sequence of the unit, an increase was found in the percentage of students' questions focusing on environmental responsibility and human involvement from the first and second lessons to the last lesson. In the first two lessons, only about $12 \%$ of students' questions focused on these issues, however at the end of the final lesson, percentage increased to almost $28 \%$ of the total number of questions collected in that lesson. This increase was mostly prominent in the category of question related to pollution and $\mathrm{CO}_{2}$ emissions, changing from about $6-7 \%$ in the first two lessons to about $16 \%$ in the final lesson (Table 3).

These results indicate that the students were interested in learning about the environmental aspects of the unit, found these issues to be relevant to their daily lives, and considered the human impact on the environment and human environmental responsibility to be an important issue.

\section{Advantages and Challenges of Engaging with the Modeling Practice and the Modeling Tool}

To investigate the advantages and challenges of engaging in the modeling practice and using the modeling tool during the unit, students' answers to the pre- and post-surveys and teacher and student post-enactment interviews were analyzed.

Although students described many advantages of using the modeling tool, about $42 \%$ of the students addressed issues related to modeling and using the modeling tool as the most difficult and challenging part of learning the ocean acidification unit in the post-unit survey. Also, less than $7 \%$ of the students mentioned using the modeling tool as the most interesting part of the unit in the post-survey (e.g., student \#41 wrote, "The most interesting part of the carbon cycles was the SageModeler. I liked it because I like using electronics for science"). To gain an in-depth perspective on the advantages and challenges students encountered when using the modeling tool, results were classified into the following emerging categories: (i) cognitive learning, (ii) working with models and data, (iii) features of the modeling tool, (iv) using technology, and (v) engagement and usability of the tool.

\section{Cognitive Learning}

In their interviews, students commented on many advantages of using the modeling tool regarding their learning. Students referred to general cognitive learning gains, issues related to learning the content topics of the ocean acidification unit, and learning about the nature of scientific models and about the practice of scientific modeling. Examples of each of these categories are provided in Table 4. 
Table 4. Effect of using the modeling tool on students' learning, based on students' post-enactment interview responses

\begin{tabular}{|c|c|}
\hline Category & Examples \\
\hline \multicolumn{2}{|c|}{ General cognitive learning "The tool helps you realize your mistakes." (student \#4) } \\
\hline & $\begin{array}{l}\text { "Helps you remember how it was connected...it's a way to organize your thoughts, if you forgot them." } \\
\text { (student \#7) }\end{array}$ \\
\hline & "The tool can be used in other lessons, very visual way to discuss difficult topics." (student \#5) \\
\hline \multirow[t]{2}{*}{$\begin{array}{l}\text { Learning the } \\
\text { content ideas }\end{array}$} & $\begin{array}{l}\text { unit's "[The modeling tool] Help learn about changes in water, didn't think about this stuff before." (student } \\
\text { \#3) }\end{array}$ \\
\hline & "[With the modeling tool] I learned about $\mathrm{CO}_{2}$ and emissions, effect on water." (stude \\
\hline \multicolumn{2}{|c|}{ Learning about nature of "We learn by using it, learning about science by using the models." (student \#5) } \\
\hline \multirow[t]{3}{*}{ models } & "I learned that many things can be connected, even indirectly." (student \#4) \\
\hline & - \\
\hline & "Scientists work with graphs and tables, it takes long time for collecting data." (student \#3) \\
\hline
\end{tabular}

\section{Working with Models and Data}

During their interviews, students reported that using the modeling tool was easy, fun, and interesting, in particular, when running the simulations and figuring out how to make the graphs (e.g., student \#9 "[Using the tool was] fun and interesting. You see what really happening"). Mrs. F. also mentioned that using the modeling tool and working with real data was interesting for the students, although she also remarked that defining the relationships between the variables was too complicated for her seventh-grade students.

Teachers and students noted several difficulties when creating models and when using the modeling tool. Thirteen percent of the students' responses in the post-survey concerned creating and setting up their models (e.g., student \#6 "Making the correct models the first time [was the most difficult part of the unit]"). Also, 13\% of the responses concerned difficulties related to using the graphs and tables, running the simulations and using the provided data sets (e.g., student \#22 "The most challenging part about it would be trying to make a graph because you have to put a lot of information on it to have it make sense"). Several students also mentioned that revising their models throughout the unit was challenging (e.g., student \#34 "Having to constantly change the models every time a new piece of evidence came up out of the water [was the most difficult part of the unit]") and also understanding the models (e.g., student \#87 "I am not the most talented in being able to understand and make models"). In their interviews, students mentioned that running and understanding the simulation was difficult (e.g., student \#10 "Running the simulations was difficult at first but when you get the hang of it, it is easy"). This indicates that the initial interactions students have with the modeling tool in the unit may have been too complex or too cognitively demanding, requiring more support from the teachers and learning materials.

\section{Features of the Modeling Tool}

In their interviews, students described many advantages of the modeling tool features and using them in the activities, including the image search tool, the variety of available images, and connecting the variables with arrows (e.g., student \#5 "The drawing part was helpful too, easy to answer a question, and "student \#10 "The pictures helps you understand how it all comes together").

Students also mentioned that they could not choose the shape of the arrows, did not have enough space for the graphs and tables on the screen (e.g., student \#4 "I want more space when working with the graphs and tables"), did not find interesting images, and had difficulty with viewing bars in the table instead of numbers. Several students encountered technical problems; These were related to malfunctions in the software or wireless connection issues. Mrs. A. also commented that some students became frustrated when receiving error messages while using the modeling tool, caused by a software malfunction that was later solved.

\section{Using Technology}

One of the main issues frequently detailed by the students and teachers regarding using the modeling tool was using technology tools in classroom. In their interviews, several students mentioned that using the software was interesting, fun, and engaging (e.g., student \#2 "It was interesting using the computers", student \#9 "Usually we don't work on computers much, it was fun. Cool to keep going and not stop [using computers]", student \#10 "[I liked] Using the computers every day"). The two teachers also supported these ideas in their interviews, remarking that it was easy for students to use the tool since they are good with technology, and that it is important for students to use computers. 


\section{Engagement and Usability of the Modeling Tool}

When asked about the usability of the modeling tool outside science class, students mentioned several applications for other classes, such as a visualization tool for mathematics (e.g., student \#5 "The tool can be used in other lessons, very visual way to discuss difficult topics", student \#10 "In math, you have tables and graphs, plug in the numbers you need to know"). Students also commented that using the modeling tool made them feel more engaged in the lessons because of its active and hands-on aspects (e.g., student \#2 "I felt more involved, not just a worksheet," student \#5 "Better than learning a text book, this is hands-on").

In summary, students and teachers had mostly positive views towards learning the ocean acidification unit and the contribution of using the modeling tool in promoting students' learning and their understanding of the nature of scientific models. The students and teachers articulated the benefits of incorporating advanced technologies in the science classroom and the usability of the tool in other contexts. However, students reported encountering several challenges when using the modeling tool, especially the complexity of using the modeling tool, working with the resulting graphs and tables, and technical issues when engaging in some features of the tool.

\section{DISCUSSION}

This study explored how integrating a computational modeling tool in a curricular unit focusing on the environmental issue of ocean acidification supported the development of students' learning, modeling practice, and attitudes towards environmental issues. Our results indicate that using the modeling tool was engaging for the students, as perceived by the participating teachers and students. However, some challenges were uncovered when using the modeling tool and learning the unit, such as the complexity of developing models and the cognitive level of the unit. This indicates that technology tools and supporting curricular materials that focus on developing students' modeling practice can support students' engagement when learning about environmental issues. However, the curriculum should be carefully designed to facilitate students' cognitive level, content knowledge, and modeling skills.

Students' interest in most of the unit's content topics increased following the enactment of the unit, and most students held positive views toward the contribution of using the modeling tool to learning the topics of the unit. This indicates that using advanced modeling tools can support middle school students' learning and engagement in environmental topics such as ocean acidification. The multiple visual representations incorporated in the modeling tool, such as images, arrows, tables, and graphs were helpful for the students, as suggested by other researchers (Ainsworth, 2006). However, some students experienced frustration when trying to work with the different representations and data sources, indicating that advanced modeling features should be gradually integrated in curricular materials, more time should be provided for students to develop their modeling practice, and teachers should have sufficient training in order to support students in the process of using advanced modeling tools. This aligns with other studies (e.g., Harrison \& Treagust, 2000) that emphasized the need to gradually scaffold students' modeling skills from simple to complex and abstract models. We suggest designers should consider reducing the cognitive load of curricular materials by providing students with opportunities to engage with the modeling practice and the modeling tool prior to the enactment of the unit. We implemented this recommendation in the following year developing an "introduction to modeling" unit that includes several activities for helping middle and high school students to learn how to use the modeling tool and how to develop appropriate models. Another possible solution for designers is to decrease the complexity of the models and ideas presented in curricular materials or slowing down the pace of introducing more complex ideas. When implementing such curricular units, teachers should be aware of their students' knowledge and abilities, and should revise the activities in the unit to accommodate their cognitive level.

Students' showed high interest and engagement with environmental issues such as human responsibility for damaging ecological habitats and the effect of human actions, like pollution from factories, on the environment. Students also held positive attitudes toward the activities in the unit. They reported enjoying using the technology tool, mentioning its contribution to their cognitive learning, modeling capabilities, and understanding of the nature of scientific models. All these indicate that the modeling tool and the curricular unit were suitable for the students. It is suggested that modeling tools could be valuable when shifting towards three-dimensional teaching, as described in A Framework for K-12 Science Education (NRC, 2012) and when implementing the Project Based Learning approach in science classrooms. This provides further empirical evidence for supporting the claim that using advanced learning tools, which is one of the core PBL features, can help students participate in activities that are normally beyond their ability (Krajcik \& Shin, 2014; Marx et al., 1997).

Many of the students mentioned issues related to using the modeling tool as the most difficult part of the unit. One possible explanation could be that the complexity level of modeling in the unit may have been too advanced for these seventh-grade students, possibly due to lack of sufficient prior knowledge about the content of the unit or the lack of experience of working with models. Another possible explanation could be that the students had 
different ideas about scientific models that were not realized when engaging with the modeling tool. The instructional sequence and modeling principles that were incorporated in the unit followed the learning progression suggested by Schwarz (2009), focusing on the practice of constructing, using, evaluating, and revising models. However, the duration of the unit may have been too short to allow students to develop deep understanding and appreciation of the modeling practice. The unit was designed to support the development of students' modeling practice, engage them in using the computer-based modeling tool, and to teach several content ideas of ocean acidification, including deforestation, $\mathrm{CO}_{2}$ transfer between Earth's spheres, ocean acidity, and impact on marine species and ecosystems. Therefore, we recommend following the modeling learning progression suggested by Schwarz (2009), allocating enough time for each step and to provide the students with appropriate opportunities to experience, internalize, and build understanding of these ideas. One possible solution for this challenge could be designing curricular units in collaboration with the teachers, as suggested in other studies (Severance et al., 2016; Schneider et al., 2016b). Teachers can provide valuable input from their experience that would help developers to better incorporate advanced modeling tools and activities that are responsive to students' capabilities.

Constructing, using, evaluating and revising models are key features of the modeling practice (Schwarz, 2009; NRC, 2012). Students in this study were provided with opportunities to engage with all of these features while developing their models in an iterative process. They continuously built their models as they broaden their understanding of the topic during the investigations carried out in the lessons. Our findings suggest that this process contributed to their affective, cognitive and behavioral engagement, as reported by the teachers and students and found in the artifacts of the unit. However, the constraints and limitations mentioned by the teachers and students should be deeply considered when designing curricular unit that include modeling tools. Units should include sufficient scaffolds to support students' modeling practice.

Using computationally advanced software was highly appreciated by the students and teachers, who expressed their interest in using more technology in science class. These findings correlate with other studies focusing on integrating technology tools in school curricula (Fretz et al., 2002; Nersessian, 1999; Wu et al., 2001), indicating that the modeling tool provides meaningful opportunity to engage students with advanced learning tools. Some students encountered software and technological malfunctions, although these issues would be expected in any newly developed software and were quickly resolved by the software developers. In line with recommendations from other studies for introducing innovative technology tools (Blumenfeld et al., 2000), we suggest that software and curricular material developers consider students' and teachers' prior conceptual and practical knowledge and capabilities when planning the lessons, activities, and teacher professional development workshops. Also, students' and teachers' cultural norms, perceptions, and expectations should be taken into account when designing curricular materials. During the enactment of the unit, teachers may not have addressed students' prior knowledge about scientific models, and curricular materials did not stress the different types of scientific models and the similarities and differences between them. Setting up an expectation or reflective discussion about the different types of models and their usability could decrease students' challenges with scientific models.

In this study we investigated students' and teachers' perceptions regarding the advantages and challenges of using an innovative modeling tool integrated in a curricular unit about ocean acidification. The study included only one enactment of the curricular unit in one rural middle school, and more data from enactments in other schools are required. Following the enactment of the unit, the ocean acidification unit has been revised to include less content topics and to provide students with more time and support to develop their modeling practice. The modeling tool was also revised in some of its features following the recommendations presented in this study, allowing students' experience with the tool to be more intuitive and easy (Bielik et al., 2018). Further research is required to investigate students' produced models, to evaluate students' three-dimensional learning in the unit, and to explore the development of students' modeling practice. Developing students' modeling practice when engaging with technology tools requires using curricular materials that are appropriate to students' prior knowledge, cognitive level, and practical capabilities and should include scaffolds that support students' learning of the tool and ideas in the unit. This study indicates that using technology modeling tools can support secondary students' learning about environmental issues, such as ocean acidification. However, integrating advanced learning tools requires careful consideration of students' prior knowledge and abilities.

\section{ACKNOWLEDGEMENTS}

This work is supported by the National Science Foundation (NSF) under grants DRL-1417809 and DRL-1417900. Any opinions, findings, conclusions or recommendations expressed in this material are those of the authors and do not necessarily reflect the views of the NSF. We wish to thank Cynthia McIntyre from the Concord Consortium and Israel Touitou from Michigan State University for their contribution to this paper. 


\section{ENDNOTE}

1- SageModeler can be freely accessed at: https:/ / learn.concord.org/building-models.

\section{REFERENCES}

Abbasi, T., \& Abbasi, S. A. (2011). Ocean acidification: The newest threat to the global environment. Critical Reviews in Environmental Science and Technology, 41(18), 1601-1663. https:/ / doi.org/10.1080/10643389.2010.481579

Ainsworth, S. (2006). DeFT: A conceptual framework for considering learning with multiple representations. Learning and Instruction, 16(3), 183-198. https:/ / doi.org/10.1016/j.learninstruc.2006.03.001

Bielik T., Damelin D., \& Krajcik J. (2018). Why do Fishermen Need Forests? Developing a Project-Based Unit with Engaging Driving Question. Science Scope, 41(6), 64-72.

Blumenfeld, P., Fishman, B. J., Krajcik, J., Marx, R. W., \& Soloway, E. (2000). Creating usable innovations in systemic reform: Scaling up technology-embedded project-based science in urban schools. Educational psychologist, 35(3), 149-164. https://doi.org/10.1207/S15326985EP3503_2

Damelin, D., Krajcik, J., McIntyre, C., \& Bielik, T. (2017). Students Making Systems Models: An Accessible Approach. Science Scope, 40(5), 78-82.

Doney, S. C., Balch, W. M., Fabry, V. J., \& Feely, R. A. (2009). Ocean acidification: A critical emerging problem for the ocean sciences. Oceanography, 22(4), 16-25. https:/ / doi.org/10.5670/oceanog.2009.93

Fauville, G., Säljö, R., \& Dupont, S. (2013). Impact of ocean acidification on marine ecosystems: Educational challenges and innovations. Marine Biology, 160(8), 1863-1874. https:/ / doi.org/10.1007/s00227-012-1943-4

Finzer, W., \& Damelin, D. (2016). Design perspective on the Common Online Data Analysis Platform. In C. E. Konold (Chair), Student thinking, learning, and inquiry with the Common Online Data Analysis Platform. Symposium conducted at the meeting of the American Educational Research Association, Washington, D.C.

Fishman, B., Marx, R. W., Blumenfeld, P., Krajcik, J., \& Soloway, E. (2004). Creating a framework for research on systemic technology innovations. The Journal of the Learning Sciences, 13(1), 43-76. https://doi.org/10.1207/s15327809j1s1301_3

Fredricks, J., \& McColskey, W. (2012). The measurement of student engagement: A comparative analysis of various methods and student self-report instruments. In S. L. Christenson, A. L. Reschly, \& C. Wylie (Eds.), Handbook of research on student engagement (pp. 763-782). New York: Springer Sciences. https:/ / doi.org/10.1007/9781-4614-2018-7_37

Fretz, E. B., Wu, H. K., Zhang, B., Davis, E. A., Krajcik, J. S., \& Soloway, E. (2002). An investigation of software scaffolds supporting modeling practices. Research in Science Education, 32(4), 567-589. https://doi.org/10.1023/A:1022400817926

Harrison, A. G., \& Treagust, D. F. (2000). A typology of school science models. International Journal of Science Education, 22(9), 1011-1026. https:/ / doi.org/10.1080/095006900416884

Hidi, S., \& Renninger, K. A. (2006). The four-phase model of interest development. Educational Psychologist, 41(2), 111-127. https://doi.org/10.1207/s15326985ep4102_4

Krajcik, J. S., \& Shin, N. (2014). Project-based learning. The Cambridge Handbook of the Learning Sciences, Second Edition (pp. 275-297). Cambridge University Press.

Krajcik, J., Codere, S., Dahsah, C., Bayer, R., \& Mun, K. (2014). Planning instruction to meet the intent of the Next Generation Science Standards. Journal of Science Teacher Education, 25(2), 157-175. https:// doi.org/10.1007/s10972-014-9383-2

Krajcik, J., McNeill, K. L., \& Reiser, B. J. (2008). Learning-goals-driven design model: Developing curriculum materials that align with national standards and incorporate project-based pedagogy. Science Education, 92(1), 1-32. https:/ / doi.org/10.1002/ sce.20240

Lehrer, R., \& Schauble, L. (2006). Cultivating model-based reasoning in science education. In K. Sawyer (Ed.), The Cambridge handbook of the learning sciences. New York: Cambridge University Press. https://doi.org/10.1017/CBO9781139519526.043

Manni, A., Sporre, K., \& Ottander, C. (2017). Emotions and values: A case study of meaning-making in ESE. Environmental Education Research, 23(4), 451-464. https:/ / doi.org/10.1080/13504622.2016.1175549

Marx, R. W., Blumenfeld, P. C., Krajcik, J. S., \& Soloway, E. (1997). Enacting project-based science. The elementary school journal, 97(4), 341-358. https:/ / doi.org/10.1086/461870

National Research Council. (2012). A framework for K-12 science education: Practices, crosscutting concepts, and core ideas. Washington, DC: The National Academies Press. https:/ / doi.org/10.17226/13165 
Nersessian, \& P. Thagard (Eds.) Model-based reasoning in scientific discovery (pp. 5-22). Boston, MA: Springer. https:/ / doi.org/10.1007/978-1-4615-4813-3

Nersessian, N. J. (1999). Model-based reasoning in conceptual change. In L. Magnani, N. J. https:/ / doi.org/10.1007/978-1-4615-4813-3_1

Nersessian, N. J. (2002). The cognitive basis of model-based reasoning in science. In P. Carruthers, S. Stich, \& M. Siegal (Eds.), The cognitive basis of science (pp. 133-153). Cambridge: Cambridge University Press. https:/ / doi.org/10.1017/CBO9780511613517.008

NGSS Lead States. (2013). Next generation science standards: For states, by states. Washington, DC: The National Academies Press. https:/ / doi.org/10.17226/18290

Passmore, C., Gouvea, J. S., \& Giere, R. (2014). Models in science and in learning science: Focusing scientific practice on sense-making. In M. R. Matthews (Ed.), International handbook of research in history, philosophy and science teaching (pp. 1171-1202). Netherlands: Springer. https://doi.org/10.1007/978-94-007-7654-8_36

Quintana, C., Reiser, B. J., Davis, E. A., Krajcik, J., Fretz, E., Duncan, R. G., ... Soloway, E. (2004). A scaffolding design framework for software to support science inquiry. The journal of the learning sciences, 13(3), 337-386. https:/ / doi.org/10.1207/s15327809j1s1303_4

Schneider, B., Krajcik, J., Lavonen, J., Salmela-Aro, K., Broda, M., Spicer, J., ... Viljaranta, J. (2016). Investigating optimal learning moments in US and Finnish science classes. Journal of Research in Science Teaching, 53(3), 400-421. https:// doi.org/10.1002/tea.21306

Schwarz, C. V., Reiser, B. J., Davis, E. A., Kenyon, L., Achér, A., Fortus, D., ... Krajcik, J. (2009). Developing a learning progression for scientific modeling: Making scientific modeling accessible and meaningful for learners. Journal of Research in Science Teaching, 46(6), 632-654. https:/ / doi.org/10.1002/tea.20311

Schwarz, C., Reiser, B. J., Acher, A., Kenyon, L., \& Fortus, D. (2012). MoDeLS: Challenges in defining a learning progression for scientific modeling. In A. C. Alonzo \& A. W. Gotwals (Eds.). Learning progressions in science: Current challenges and future directions (pp. 101-137). Rotterdam: Sense Publishers. https:/ / doi.org/10.1007/978-94-6091-824-7_6

Severance, S., Penuel, W. R., Sumner, T., \& Leary, H. (2016). Organizing for teacher agency in curricular co-design. Journal of the Learning Sciences, 25(4), 531-564. https:/ / doi.org/10.1080/10508406.2016.1207541

Shepardson, D. P., Choi, S., Niyogi, D., \& Charusombat, U. (2011). Seventh grade students' mental models of the greenhouse effect. Environmental Education Research, 17(1), https:/ / doi.org/10.1080/13504620903564549

Skinner, E. A., Marchand, G., Furrer, C., \& Kindermann, T. (2008). Engagement and disaffection in the classroom: Part of a larger motivational dynamic. Journal of Educational Psychology, 100(4), 765-781. https:/ / doi.org/10.1037/a0012840

Weizman, A., Schwartz, Y., \& Fortus, D. (2008). The driving question board. The Science Teacher, 75(8), 33.

Wilcoxon, F. (1945). Individual comparisons by ranking methods. Biometrics bulletin, 1(6), 80-83. https: / / doi.org/10.2307/3001968

Windschitl, M., Thompson, J., \& Braaten, M. (2008). Beyond the scientific method: Model-based inquiry as a new paradigm of preference for school science investigations. Science Education, 92(5), 941-967. https:// doi.org/10.1002/sce.20259

Wu, H. K., Krajcik, J. S., \& Soloway, E. (2001). Promoting understanding of chemical representations: Students' use of a visualization tool in the classroom. Journal of research in science teaching, 38(7), 821-842. https:/ / doi.org/10.1002/tea.1033 


\section{APPENDICES}

\section{Appendix 1}

\section{Students' semi-structured interview questions}

- What was the purpose of building your model?

- Why do you think we use models in science class?

- What was the most interesting part of learning about the (unit topic)?

- What was the most interesting part of using the modeling tool?

- What was the most challenging/difficult part of learning about (unit topic)?

- What was the most challenging/difficult of using the modeling tool?

- Do you have any suggestions about how we could improve the modeling tool or the lessons?

\section{Appendix 2}

\section{Teachers' semi-structured interview questions}

- What was your experience teaching the unit?

- Let's discuss the learning goals of the unit. What were the learning goals you had for students? How did the unit support students in achieving these learning goals?

- What worked well? Which activities were the most engaging and interesting for the students and for you?

- What were the main challenges in teaching and learning the unit?

- Did you encounter any difficulties (e.g., equipment, teacher training preparation time, assessment) for you or for the students?

- Did you make any changes or modifications to the lessons plan? If so, why?

- Describe the level of engagement students had in constructing and revising their models.

- Was the interaction with the modeling tool effective? Why/ why not?

- What was your experience teaching with the modeling tool?

- Were the curricular materials detailed and supportive enough?

- What other lessons would you consider using the modeling tool for?

\section{http://www.ejmste.com}

